\title{
Testosterone and Cortisol in Relation to Aggression in a Non-Clinical Sample of Boys and Girls
}

\author{
Evelien Platje $^{1,2,3 *}$, Arne Popma ${ }^{1,4}$, Robert R.J.M. Vermeiren ${ }^{1,5}$, Theo A.H. Doreleijers ${ }^{1}$, \\ Wim H.J. Meeus ${ }^{6,7}$, Pol A.C. van Lier ${ }^{8}$, Hans M. Koot ${ }^{8}$, Susan J.T. Branje ${ }^{6}$, and Lucres M.C. Jansen ${ }^{1}$ \\ ${ }^{1}$ Department of Child and Adolescent Psychiatry, VU University Medical Center, Amsterdam, The Netherlands \\ ${ }^{2}$ Clinical Child and Adolescent Studies, Leiden University, Leiden, The Netherlands \\ ${ }^{3}$ Leiden Institute for Brain and Cognition, Leiden University, Leiden, The Netherlands \\ ${ }^{4}$ Department of Criminal Law and Criminology, Leiden University, Leiden, The Netherlands \\ ${ }^{5}$ Curium - Leiden University Medical Center, Leiden, The Netherlands \\ ${ }^{6}$ Research Center Adolescent Development, Utrecht University, Utrecht, The Netherlands \\ ${ }^{7}$ Tilburg School of Behavioral and Social Sciences, Tilburg University, Tilburg, The Netherlands \\ ${ }^{8}$ Department of Developmental Psychology, VU University, Amsterdam, The Netherlands
}

: : : : : : : : : : : : : : : : : : : : : : : : : : : : : : : : : : :

Testosterone and cortisol have been proposed to jointly regulate aggressive behavior. However, few empirical studies actually investigated this joint relation in humans, and reported inconsistent findings. Also, samples in these studies were small and/or specific, and consisted largely of males. Therefore, in the current study testosterone and cortisol in relation to aggression were investigated in a non-clinical sample of 259 boys and girls (mean age 16.98 years, $S D=0.42,56 \%$ boys). A positive testosterone/ cortisol ratio, that is, high testosterone relative to cortisol, was found to be associated with aggressive behavior, explaining $7 \%$ of the variance. The interaction between testosterone and cortisol was not related to aggressive behavior and gender differences were not found. The ratio may reflect an imbalance leaving the individual more prone to rewarding aspects, than fearful of negative implications of aggressive behavior. Current findings indicate that this relation can be generalized to aggression in non-clinical adolescents. Aggr. Behav. 41:478-487, 2015. (C) 2015 Wiley Periodicals, Inc.

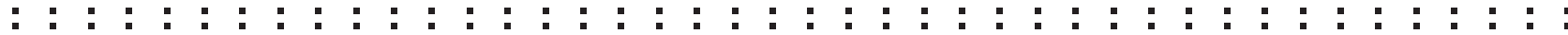

Keywords: aggression; testosterone; cortisol

\section{INTRODUCTION}

Testosterone and cortisol have been proposed to jointly regulate aggressive behavior (Mehta \& Josephs, 2010; Montoya, Terburg, Bos, \& van Honk, 2012; Terburg, Morgan, \& van Honk, 2009; Van Honk, Harmon-Jones, Morgan, \& Schutter, 2010). However, the empirical studies that actually investigated this dual-hormone hypothesis (Mehta \& Josephs, 2010) in humans reported inconsistent findings (Dabbs, Jurkovic, \& Frady, 1991; Denson, Mehta, \& Ho, 2012; Glenn, Raine, Schug, Gao, \& Granger, 2011; Mazur \& Booth, 2014; Mehta \& Josephs, 2010; Popma, Vermeiren, et al., 2007; RomeroMartinez, Gonzalez-Bono, Lila, \& Moya-Albiol, 2013; Scerbo \& Kolko, 1994; Tackett, Herzhoff, Harden, PageGould, \& Josephs, 2014; Welker, Lozoya, Campbell, Neumann, \& Carré, 2014). Moreover, samples in these studies were often rather small and/or specific (e.g., delinquent adolescents or clinic-referred disruptive children), and consisted largely of males. Therefore, the aim of the current study was to investigate the joint relation of testosterone and cortisol with aggression in a larger non-clinical sample of adolescent boys and girls.

It has been proposed that aggression is linked specifically to high testosterone levels in combination with low cortisol levels (Mehta \& Josephs, 2010;

Data of the RADAR study were used. RADAR has been financially supported by main grants from The Netherlands Organisation for Scientific Research, Stichting Achmea Slachtoffer en Samenleving (SASS), and the VU University Amsterdam and Utrecht University. This project has been supported by the Foundation "De Drie Lichten" in The Netherlands. The authors have no conflict of interest to declare. We sincerely thank all participating families and schools for taking part in this study.

${ }^{*}$ Correspondence to: Evelien Platje, Clinical Child and Adolescent Studies, Leiden University, Wassenaarseweg 52, 2333 AK Leiden, The Netherlands.E-mail: e.platje@fsw.leidenuniv.nl

Received 28 January 2014; Accepted 13 January 2015

DOI: $10.1002 / \mathrm{ab} .21585$

Published online 3 March 2015 in Wiley Online Library (wileyonlinelibrary.com). 
Montoya et al., 2012; Terburg et al., 2009; Van Honk \& Schutter, 2006). Testosterone and cortisol are the end products of the hypothalamic-pituitary-gonadal (HPG) and the hypothalamic-pituitary-adrenal (HPA) axes, respectively. High levels of testosterone independently are merely weakly associated with aggression in humans, whereas in animal studies this relation is well established (meta-analysis by Archer, Graham-Kevan, and Davies (2005). Similarly, low levels of cortisol have been reported to correlate with aggressive and antisocial behavior (e.g., De Vries-Bouw et al., 2012; McBurnett, Lahey, Rathouz, \& Loeber, 2000; Platje et al., 2013; Popma, Doreleijers, et al., 2007; Shoal, Giancola, \& Kirillova, 2003), but not consistently (see meta-analysis by Alink et al., 2008). However, the HPG and HPA axes mutually inhibit one another (Viau, 2002); testosterone can inhibit HPA axis function at the level of the hypothalamus (Viau \& Meaney, 1996), as well as downstream pathways (Carsia, Reisch, Fennell, \& Weber, 1987; Colby, Gaskin, \& Kitay, 1973; McCormick, Linkroum, Sallinen, \& Miller, 2002; Nowak, Neri, Nussdorfer, \& Malendowicz, 1995), and cortisol inhibits HPG axis activity at all levels (Johnson, Kamilaris, Chrousos, \& Gold, 1992; Tilbrook, Turner, \& Clarke, 2000; Viau, 2002). On a psychological level, HPG axis activity is related to approach in rewarding situations, whereas HPA axis activity is related to withdrawal from fearful situations (Schulkin, 2003). Together they thus maintain a healthy balance between reward and fear. As such, it has been suggested that when this balance is disturbed, with high levels of testosterone and concurrent low levels of cortisol, an individual may attend to the more rewarding aspects of aggression, rather than the more negative aspects of aggression (Denson et al., 2012; Montoya et al., 2012; Terburg et al., 2009; Van Honk \& Schutter, 2006).

This theory has largely been based on the finding from a study by Dabbs et al. (1991), who reported that cortisol moderated the correlation between testosterone and violent crime in 113 late-adolescent male offenders. Specifically, basal testosterone was positively correlated with violent behavior, but only among individuals with relatively low basal cortisol concentrations. In the two decades that followed, relatively few studies actually investigated this relation, with inconsistent results. In a similar sample of 103 delinquent male adolescents, Popma, Vermeiren, et al. (2007) also found a positive relationship between basal testosterone and overt aggression in adolescents with low basal cortisol levels, but not in those with high cortisol levels. Recently, Tackett et al. (2014) also reported that in 106 community boys and girls high basal testosterone was associated with self-reported externalizing in those with low basal cortisol. Similarly, in 94 students enrolled in a university course basal testosterone was positively related to dominance, but only in those with low basal cortisol levels (Mehta \& Josephs, 2010). Other studies reported less consistent results. In 40 clinic-referred disruptive children no interaction between testosterone and cortisol was found in relation to a general aggression questionnaire (Scerbo \& Kolko, 1994). In 53 young women reactive aggression was associated with a different direction of the interaction, that is, concurrent high levels of basal testosterone and cortisol (Denson et al., 2012). A similar interaction was found in a relatively large sample of 237 undergraduate students with psychopathic traits, which are associated with aggression and a lack of fear (Welker et al., 2014). Recently, in a very large sample of 4462 male army veterans testosterone was associated with deviance, but this was not moderated by cortisol levels (Mazur \& Booth, 2014).

The above-mentioned studies investigated the dualhormone hypothesis by examining the interaction between testosterone and cortisol. Besides an interaction, the interconnectedness of the HPG and HPA axes can also be described by the ratio between testosterone and cortisol (Glenn et al., 2011; Romero-Martinez et al., 2013; Terburg et al., 2009). The ratio reflects the relative level of testosterone to cortisol within each individual, whereas the interaction treats testosterone and cortisol as two distinct variables. Indeed, a positive relation between the ratio of baseline testosterone to cortisol reactivity and psychopathic traits was found in 178 general population adults (Glenn et al., 2011), and intimate partner violence perpetrators had higher testosterone to cortisol ratios than controls in preparation for and after acute stress (RomeroMartinez et al., 2013). Comparable results were found for girls with conduct disorder (CD), where aggressive $\mathrm{CD}$ symptoms were related to a lower ratio of cortisol to dehydroepiandrosterone (DHEA), a testosterone precursor (Pajer et al., 2006). Although the direction of the relation between the two hormones and aggression was similar to the findings of Dabbs et al. (1991) and Popma, Vermeiren, et al. (2007) in (late) adolescents, Glenn et al. (2011) found no interactions between testosterone and cortisol, while Romero-Martinez et al. (2013) and Pajer et al. (2006) did not examine interactions. In students enrolled in a university course, however, the interaction between testosterone and cortisol was related to dominance, whereas the testosterone/cortisol ratio was only marginally associated with dominance in a mixed-gender sample (Study 1, Mehta \& Josephs, 2010), and unrelated in a male sample (Study 2, Mehta \& Josephs, 2010).

In females the relation between testosterone, cortisol and aggression may be different compared to males. Testosterone is not only lower in women compared to men, it is also produced differently. Whereas in men testosterone is synthesized by the Leydig cells of the 
testes, part of the HPG axis, in women approximately half of testosterone is produced by the adrenal cortex, which is part of the HPA axis (Burger, 2002). To date, only three studies investigated the dual-hormone hypothesis in mixed-gender samples studying respectively dominance, externalizing behavior and psychopathic traits (Study 1, Mehta \& Josephs, 2010; Tackett et al., 2014; Welker et al., 2014). Dominance was associated with an interaction indicating high testosterone and low cortisol levels in both men and women, as well as a marginally significant association with the ratio (Study 1, Mehta \& Josephs, 2010). Tackett et al. (2014) did not specifically mention testosterone-cortisol interactions for boys and girls separately, but reported that these analyses confirmed the overall pattern of high testosterone and low cortisol in relation to externalizing behavior. Psychopathic traits, however, were associated with a testosterone-cortisol interaction in men only, ánd indicated a positive relation with testosterone in individuals with high cortisol levels (Welker et al., 2014). The two studies using female samples (Denson et al., 2012; Pajer et al., 2006) yielded contrasting results as well. Although Glenn et al. (2011) and Scerbo and Kolko (1994) investigated mixed-gender samples, the large majority in these studies $88 \%$ and $92 \%$ respectively) was male, and gender comparisons could not be made. Gender differences have been investigated for the ratio of testosterone to cortisol only once, and regarding aggressive behavior, men and women have not been compared on the joint relation of testosterone and cortisol.

As such, although the proposed interplay between testosterone and cortisol in relation to aggression is likely to aid in understanding its underlying mechanisms, more research is required before further inferences can be drawn. More specifically, the generalizability of the finding of concurrent high testosterone and low cortisol in relation to aggression in non-clinical and female samples needs further elucidation. Therefore, in the current study testosterone and cortisol in relation to aggression were studied in a larger non-clinical sample of both boys and girls. In order to investigate the severity of aggressive behavior more comprehensively, both linear and categorical analyses were performed. As different researchers have taken different statistical approaches to investigate the joint relation of testosterone and cortisol, the current study further implemented both the interaction between testosterone and cortisol, as well as the ratio.

\section{METHODS}

\section{Participants}

Participants were 259 adolescents (144 boys and 115 girls), with a mean age of 16.98 years $(S D=0.42)$. They were recruited from the Research on Adolescent Development And Relationships (RADAR) study. RADAR is a Dutch population-based cohort study, with oversampling $(50 \%)$ of boys and girls with a borderline-clinical score on the externalizing scale of the Teacher's Report Form (TRF, Achenbach) at age 11. Behavioral assessments were subsequently assessed annually at the participants' home, and between January 2010 and January 2011 all participants were invited to participate in a lab session. This paper deals with the behavioral assessment performed at age 17 in February and March of 2010, and the lab session, which included assessment of cortisol and testosterone levels. On average aggression assessment took place 116 days before the lab session ( $S D=75$ days).

All participants and their parents provided written informed consent and received a reimbursement for their participation. The RADAR study was approved by the responsible medical ethics committee, and was conducted in accordance with the Declaration of Helsinki.

Of the 418 adolescents who participated in the RADAR study in 2010, 303 participated in the lab session. The 303 participants did not differ from those not participating in the lab session on age, gender or level of aggressive behavior (all $P>.10$ ). Forty participants were unable to produce sufficient saliva to assay for testosterone and cortisol, they did not differ from the 263 adolescents for whom sufficient saliva was sampled on age, gender or level of aggressive behavior (all $P>.10$ ). Of these 263 adolescents, four participants did not provide information on alcohol or nicotine use, resulting in 259 adolescents included in the final analyses (see Table I).

\section{Aggressive Behavior}

Aggressive behavior was assessed by means of the Youth Self Report (YSR; Achenbach, 1991), administered to the adolescents. The aggression subscale consisted of 19 items assessing physical acts against persons or things (i.e., fighting, being cruel to others) and verbal aggression (e.g., screaming, arguing), which are scored on a three-point scale $(0=$ not true, $1=$ somewhat true, $2=$ very true or often true). Cut-off scores distinguish scores in the borderline and clinical range from those in the normal range (Achenbach, 1991; Verhulst, Van der Ende, \& Koot, 1997). Good reliability and validity have been reported for the Dutch version (Verhulst et al., 1997). The reliability of the aggression subscale of the YSR in the current study is high $($ Cronbach's alpha $=.82)$.

\section{Testosterone and Cortisol}

Testosterone and cortisol were assessed during resting conditions of the lab session. Before the saliva sample 
TABLE I. Descriptive Statistics

\begin{tabular}{|c|c|c|c|c|c|c|c|c|}
\hline & \multicolumn{2}{|c|}{ All Participants } & \multicolumn{2}{|c|}{ Boys } & \multicolumn{2}{|c|}{ Girls } & \multirow[b]{2}{*}{$t$-test $/ X^{2}$} & \multirow[b]{2}{*}{$P$} \\
\hline & Mean/n & $S D / \%$ & Mean/n & $S D / \%$ & Mean/n & $S D / \%$ & & \\
\hline $\mathrm{N}$ & 259 & & 144 & $56 \%$ & 115 & $44 \%$ & & \\
\hline Age & 16.98 & 0.42 & 17.00 & 0.43 & 16.95 & 0.40 & 0.77 & .445 \\
\hline Aggressive behavior & 6.31 & 5.17 & 6.58 & 5.65 & 5.97 & 4.51 & 0.93 & .353 \\
\hline Cortisol (nmol/L) & 6.31 & 3.26 & 6.91 & 3.46 & 5.52 & 3.46 & 3.47 & .001 \\
\hline Testosterone $(\mathrm{pmol} / \mathrm{L})$ & 182.78 & 114.43 & 266.87 & 80.71 & 77.50 & 36.75 & 23.30 & $<.001$ \\
\hline Alcohol use & 44 & $17 \%$ & 33 & $23 \%$ & 11 & $9 \%$ & 8.08 & .005 \\
\hline Nicotine use & 64 & $25 \%$ & 35 & $24 \%$ & 29 & $25 \%$ & 0.03 & .886 \\
\hline
\end{tabular}

Note. Untransformed levels of testosterone and cortisol are presented, whereas in the analyses these were standardized. Alcohol and nicotine used in the 24 hr before sampling.

was taken, participants were instructed on the protocol of the lab session, watched empathy inducing film clips (30 min) and performed two neurocognitive tasks (30 min). Next, a 20-min break was introduced and they filled in a few questionnaires. One of the questions concerned their stress levels; on average they scored $20.94(S D=18.81)$ on a scale from 0 to 100 (with 0 indicating no stress). At the end of this break the saliva sample was collected. Testosterone and cortisol were assessed in one saliva sample obtained by passive drool. The average time of collection was 3:58 p.m. $(S D=26$ min). After this sample a stress task started.

Saliva was stored uncentrifuged at $-20^{\circ} \mathrm{C}$ until analysis. Testosterone was analyzed in duplicate using an in-house competitive radio-immunoassay employing a polyclonal anti-testosterone-antibody (Dr. Pratt AZG 3290). $\left[1,2,6,7-{ }^{3} \mathrm{H}\right]$-Testosterone (NET370250UC, PerkinElmer) was used as a tracer following chromatographic verification of its purity. The lower limit of detection was $20 \mathrm{pmol} / \mathrm{L}$. The mean and intra- and inter-assay coefficients of variation were $5 \%$ and $11 \%$ respectively. Cortisol was analyzed using electrochemiluminescence immunoassay (ECLIA). The lower detection limit was $.5 \mathrm{nmol} / \mathrm{L}$, with mean intra-assay and inter-assay coefficients of variation of $3.4 \%$ and $12.2 \%$.

\section{Control Variables}

Control variables were assessed at the lab session. During the lab session temperature and humidity of the test room were recorded, and the season of saliva sampling was taken into account. Intake of food, drinks, alcohol, nicotine and drugs, as well as physical exercise, within the last $24 \mathrm{hr}$, were assessed. Stressful situations in the past year, such as sexual assault, physical assault, and being threatened with violence, were assessed with a questionnaire based on the International Crime Victims Survey (ICVS; Nieuwbeerta, 2002). Medication use, diseases, physical and dental conditions (including allergies and oral bleeding), body mass index (BMI), as well as menstrual phase and contra-conceptive (OC) use for females were assessed as well. ${ }^{1}$ Pubertal status was assessed a year prior to the other assessments, at age 16 by means of a modification of the Pubertal Development Scale ${ }^{2}$ (PDS; Petersen, Crockett, Richards, $\&$ Boxer, 1988). The time between the assessment of aggression and the lab session in which testosterone and cortisol were assessed was calculated as a control variable as well.

\section{Statistical Analyses}

Outliers in testosterone and cortisol were winsorized at $3 S D$ above the mean $(n=6)$. As the distribution of cortisol values was positively skewed, a square root transformation was performed, after which values were normally distributed.

Testosterone and cortisol values were standardized separately for boys and girls by means of a Ztransformation (Study 1, Mehta \& Josephs, 2010). For the testosterone to cortisol ratio a T-transformation (mean $50 ; S D 10$ ) was performed separately for boys and girls. Individual testosterone/cortisol ratio scores were calculated, as in Hermans, Ramsey, and van Honk (2008). The testosterone/cortisol ratio scores were normally distributed and outliers were not present.

Control variables associated with aggression as well as testosterone and/or cortisol were controlled for in the final analyses. Four linear regression analyses were performed with aggression as the dependent variable. First, main effects of standardized cortisol and testosterone respectively were examined in two separate analyses. In a third model, standardized cortisol and testosterone

\footnotetext{
${ }^{1}$ Four female participants (3\%) had not yet menstruated, of those who had, $82(73 \%)$ experienced a regular cycle with an average of 27.41 days $(S D=2.55)$. Sixty-one female participants $(52 \%)$ used hormonal birth control. Of those who did not $(n=36)$, the first day of the last menstruation was equally distributed; $n=11: 0-7$ days ago; $n=11: 8-14$ days ago; $n=11: 15-21$ days ago, and $n=3: 22-28$ days ago.

${ }^{2}$ At age $16,96 \%$ of the participants reported experiencing pubertal development in the last $0.5-1$ year, and $34 \%$ reported full maturation.
} 
were entered simultaneously in Step 1. In Step 2, the interaction term between testosterone and cortisol was added. In the fourth model, only the ratio of testosterone to cortisol was entered as a predictor. Gender by joint testosterone-cortisol effects were tested in each model. If interaction effects with gender were not found, gender was controlled for in the analyses that included both boys and girls.

Post hoc, categorical analyses on associations of testosterone and cortisol with aggression were further examined with logistic regression analyses, to assess whether borderline-clinical aggressive behavior can be distinguished from aggressive behavior in the normal range. The same control variables as in the linear regression analyses, and gender, were controlled. Four logistic regression analyses were performed, with the likelihood of scoring in the borderline-clinical range of aggression as dependent variable. As predictors, the same four models were tested as in the linear regression analyses.

\section{RESULTS}

The average score of all participants on aggressive behavior fell within the normal range of aggressive behavior, 242 (90\%) of the participants scored within the normal range, and $25(10 \%)$ in the borderline-clinical range.

For all control variables differences in or associations with aggression as well as testosterone and/or cortisol were examined. Only for nicotine (higher aggression scores $t(257)=3.48, P=.001$, and higher cortisol $t(257)=1.52$, $P<.001)$ and alcohol used in the $24 \mathrm{hr}$ before saliva sampling (higher aggression scores $t(257)=2.90$, $P=.004$, and slightly lower testosterone $t(257)=1.62$, $P=$.107) differences were found, and these were therefore controlled in the analyses. ${ }^{3}$

In Table I descriptive statistics are shown. It can be seen that boys showed higher levels of cortisol, testosterone, and more often reported to have used alcohol in the $24 \mathrm{hr}$ before sampling. In Table II it can be seen that cortisol and testosterone are positively correlated for the entire sample, but not for boys or girls separately. Also, the ratio of testosterone to cortisol is negatively correlated to cortisol and positively to testosterone for the entire sample, as well as for boys and girls separately.

\footnotetext{
${ }^{3}$ Analyses were also run without controlling for alcohol and nicotine use, results can be found in Table IV in the additional material. All effects of cortisol and testosterone are no longer significant, and a trend is observed for the ratio in association with aggression for all participants. Hence, for participants of whom $17-25 \%$ has used these substances, alcohol and nicotine use confound the relation between testosterone, cortisol, and aggressive behavior.
}

Table III shows the results of the linear regression analyses. A negative association of cortisol with aggressive behavior was found for all participants, indicating that those with lower cortisol levels reported higher levels of aggression (see Fig. 1). This effect remained present after controlling for testosterone. No main effect of testosterone was found in association with aggressive behavior.

The interaction variable testosterone $\times$ cortisol was also not significantly related to aggressive behavior. However, a positive ratio of testosterone to cortisol was found to be associated with aggressive behavior for all participants, explaining $7 \%$ of the variance in aggressive behavior (see Fig. 2). ${ }^{4}$

Gender differences were examined by adding a gender $\times$ testosterone $\times$ cortisol interaction, and a gender $\times$ testosterone/cortisol ratio. The interaction terms were not significant for gender $\times$ testosterone $\times$ cortisol $(B=.30$ [-1.09-1.69], $P=.671)$ nor for the gender $\times$ testosterone/cortisol ratio $(B=-.00$ $[-.00-.00], P=.253)$ in association with aggressive behavior. This indicates that the association between aggressive behavior and (1) the testosterone $\times$ cortisol interaction, and (2) the testosterone/cortisol ratio, are statistically equivalent in boys and girls.

Analyses for boys and girls separately showed a trend towards a negative association between cortisol and aggressive behavior for boys, which remained present after controlling for testosterone. Cortisol was not associated with aggressive behavior in girls. For girls a trend towards a positive association between testosterone and aggressive behavior appeared, when controlling for cortisol. Analyses for boys and girls separately confirmed that for neither boys nor girls the testosterone $\times$ cortisol interaction was associated with aggressive behavior. The direction of the relation between the testosterone/cortisol ratio was the same for boys and girls, confirming the nonsignificant interaction between the ratio and gender, although for girls only a positive ratio was significantly associated with aggressive behavior.

Post hoc, we examined whether the likelihood that participants show aggression in the borderline-clinical range ( $n=25$, of whom 5 were girls) versus aggression in the normal range, is related to testosterone and cortisol. Logistic regression analyses controlling for gender,

\footnotetext{
${ }^{4}$ Because this concerns a population-based sample with over-sampling, the analyses were repeated excluding those with aggressive behavior in the clinical range. It appeared that all effects are also present in this actual nonclinical sample. Analyses were also repeated including the outliers, results remained similar, although the trend of cortisol for aggressive behavior in boys when corrected for testosterone, and the trend for the ratio predicting aggression in the borderline-clinical range versus normal range aggression were no longer significant.
} 
TABLE II. Correlations

\begin{tabular}{|c|c|c|c|c|c|c|c|}
\hline & \multicolumn{3}{|c|}{ All Participants } & \multicolumn{4}{|c|}{ Separate Per Gender } \\
\hline & 2 & 3 & 4 & 1 & 2 & 3 & 4 \\
\hline 1. Aggressive behavior & -.05 & .08 & .11 & - & -.04 & .14 & .14 \\
\hline 2. Cortisol $^{\mathrm{a}}$ & & $.26^{* * *}$ & $-.62^{* * *}$ & .09 & - & .16 & $-.65^{* * *}$ \\
\hline 3. Testosterone $\mathrm{a}^{\mathrm{a}}$ & & & $.33^{* * *}$ & .03 & .14 & - & $.61^{* * *}$ \\
\hline 4. Testosterone/cortisol ratio ${ }^{a}$ & & & & .09 & $-.62^{* * *}$ & $.65^{* * *}$ & - \\
\hline
\end{tabular}

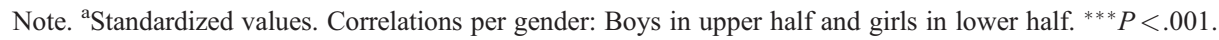

TABLE III. Results of the Four Linear Regression Analyses Predicting Aggression

\begin{tabular}{|c|c|c|c|c|c|c|c|c|c|c|c|c|c|c|}
\hline & & & \multicolumn{4}{|c|}{ All Participants } & \multicolumn{4}{|c|}{ Boys } & \multicolumn{4}{|c|}{ Girls } \\
\hline & & & $B$ & $95 \% \mathrm{CI}$ & $P$ & Adj. $R^{2}$ & $B$ & $95 \% \mathrm{CI}$ & $P$ & Adj. $R^{2}$ & $B$ & $95 \% \mathrm{CI}$ & $P$ & Adj. $R^{2}$ \\
\hline & & Main effects & & & & & & & & & & & & \\
\hline Model 1 & & Cortisol & -.64 & -1.27 to -.00 & .050 & .06 & -.83 & -1.75 to .09 & .077 & .09 & -.40 & -1.26 to .46 & .362 & .02 \\
\hline Model 2 & & $\begin{array}{l}\text { Testosterone } \\
\text { Combined effects }\end{array}$ & .23 & -.041 to .87 & .477 & .05 & -.05 & -1.00 to .90 & .915 & .07 & .65 & -.20 to 1.50 & .131 & .03 \\
\hline \multirow[t]{3}{*}{ Model 3} & Step 1 & Cortisol & -.68 & -1.32 to -.04 & .038 & .06 & -.83 & -1.76 to .10 & .078 & .09 & -.51 & -1.38 to .35 & .242 & .03 \\
\hline & & Testosterone & .31 & -.32 to .96 & .325 & & .05 & -.90 to -.99 & .921 & & .73 & -.13 to 1.58 & .093 & \\
\hline & Step 2 & $\begin{array}{l}\text { Testosterone } \times \text { cortisol } \\
\text { interaction }\end{array}$ & .20 & -.47 to .88 & .551 & .06 & .26 & -.72 to 1.23 & .605 & .08 & -.01 & -.95 to .94 & .992 & .03 \\
\hline Model 4 & & Testosterone/cortisol ratio & 2.46 & .13 to 4.79 & .039 & .07 & 2.13 & -1.23 to 5.49 & .212 & .08 & 3.20 & .10 to .38 & .049 & .04 \\
\hline
\end{tabular}

Note. Results are controlled for gender (for analyses including all participants), alcohol and nicotine use in the last $24 \mathrm{hr}$. Cortisol and testosterone values are standardized; $B$ 's for main effects and interaction are based on $Z$-scores, $B$ 's for the ratio are based on $T$-scores.

nicotine and alcohol use, showed no main effect for cortisol $(\mathrm{OR}=.68$ [.42-1.10], $P=.114$, Nagelkerke $\left.R^{2}=.11\right)$, or testosterone $(\mathrm{OR}=1.14 \quad[.74-1.75]$, $P=.567$, Nagelkerke $R^{2}=.09$ ). When controlling for testosterone, a trend was found for lower cortisol levels for those in the borderline-clinical range than those with aggression in the normal range $(\mathrm{OR}=.66$ [.41-1.08], $P=.095$, Nagelkerke $\left.R^{2}=.11\right)$. The interaction variable testosterone $\times$ cortisol was not significantly related to aggressive behavior $(\mathrm{OR}=1.10[.70-1.74], P=.670$,

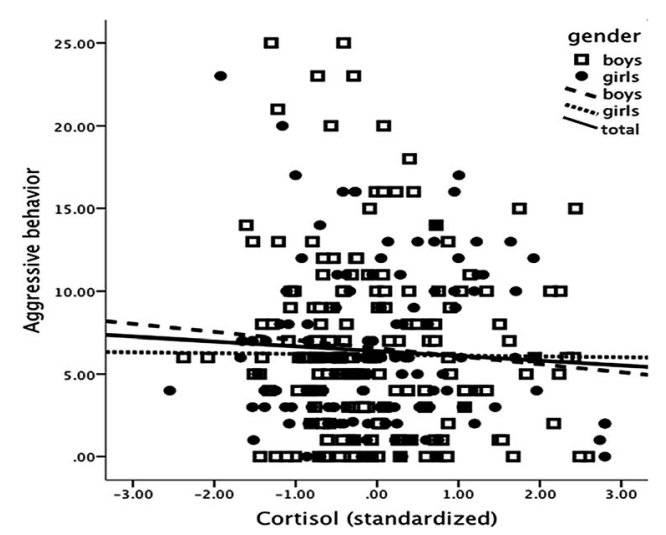

Fig. 1. Scatterplot of the association between aggressive behavior and cortisol levels, presented for boys, girls, and all participants.
Nagelkerke $\left.R^{2}=.11\right)$ and a trend towards a higher ratio in the borderline-clinical range of aggressive behavior was found $(\mathrm{OR}=3.80$ [.84-17.32], $P=.084$, Nagelkerke $\left.R^{2}=.11\right)$.

\section{DISCUSSION}

It has been proposed that, in adults and adolescents, aggression is related to high levels of testosterone in combination with low levels of cortisol. This hormonal

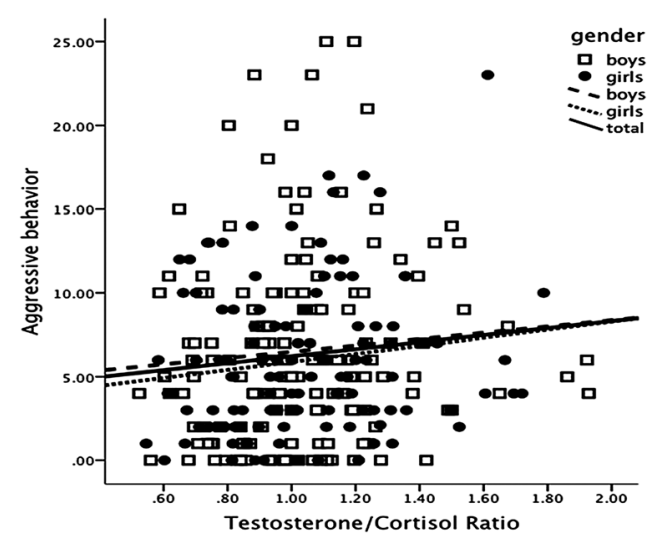

Fig. 2. Scatterplot of the association between aggressive behavior and testosterone/cortisol ratio, presented for boys, girls, and all participants. 
TABLE IV. Results of the Four Linear Regression Analyses Predicting Aggression Without Correction for Alcohol and Nicotine Use

\begin{tabular}{|c|c|c|c|c|c|c|c|c|c|c|c|c|c|c|}
\hline & & & \multicolumn{4}{|c|}{ All Participants } & \multicolumn{4}{|c|}{ Boys } & \multicolumn{4}{|c|}{ Girls } \\
\hline & & & $B$ & $95 \% \mathrm{CI}$ & Adj. $R^{2}$ & $P$ & $B$ & $95 \% \mathrm{CI}$ & Adj. $R^{2}$ & $P$ & $B$ & $95 \% \mathrm{CI}$ & Adj. $R^{2}$ & $P$ \\
\hline & & Main effects & & & & & & & & & & & & \\
\hline Model 1 & & Cortisol & -.33 & -.97 to .30 & .00 & .303 & -.47 & -1.40 to .46 & .00 & .318 & -.16 & -1.00 to .68 & .00 & .709 \\
\hline Model 2 & & $\begin{array}{l}\text { Testosterone } \\
\text { Combined effects }\end{array}$ & .40 & -.24 to 1.04 & .00 & .223 & .21 & -.74 to 1.15 & .00 & .664 & .63 & -.21 to 1.47 & .01 & .140 \\
\hline \multirow[t]{2}{*}{ Model 3} & Step 1 & $\begin{array}{l}\text { Cortisol } \\
\text { Testosterone }\end{array}$ & $\begin{array}{r}-.40 \\
.46\end{array}$ & $\begin{array}{l}-1.04 \text { to } .24 \\
-.19 \text { to } 1.11\end{array}$ & .00 & $\begin{array}{l}.217 \\
.163\end{array}$ & $\begin{array}{r}-.51 \\
.29\end{array}$ & $\begin{array}{l}-1.45 \text { to } .43 \\
-.67 \text { to } 1.24\end{array}$ & .00 & $\begin{array}{l}.283 \\
.553\end{array}$ & $\begin{array}{r}-.27 \\
.67\end{array}$ & $\begin{array}{l}-1.11 \text { to } .58 \\
-.18 \text { to } 1.55\end{array}$ & .01 & $\begin{array}{l}.537 \\
.121\end{array}$ \\
\hline & Step 2 & $\begin{array}{c}\text { Testosterone } \times \\
\text { cortisol } \\
\text { interaction }\end{array}$ & .24 & -.44 to .93 & .00 & .486 & .38 & -.61 to 1.38 & .00 & .451 & -.01 & -.97 to .95 & .00 & .984 \\
\hline Model 4 & & $\begin{array}{l}\text { Testosterone/cortisol } \\
\text { ratio }\end{array}$ & 2.09 & -.26 to 4.46 & .01 & .081 & 1.87 & -1.56 to 5.30 & .00 & .283 & 2.39 & -.76 to 5.55 & .01 & .136 \\
\hline
\end{tabular}

Note. Results are controlled for gender (for analyses including all participants). B's for main effects and interaction are based on $Z$-scores, $B$ 's for the ratio are based on $T$-scores.

interrelation may aid in understanding individual differences in the occurrence of aggressive behavior. Until now, research mainly focused on specific (i.e., delinquent adolescents or clinic-referred disruptive children), small and/or male samples, and results are inconclusive. The present study aimed to examine the generalizability of the relation between aggression and high testosterone combined with low cortisol to a non-clinical sample of male and female adolescents. The current findings indicate that this relation is indeed present in non-clinical adolescents. The ratio of testosterone to cortisol explained $7 \%$ of the variance in aggressive behavior. The interaction between testosterone and cortisol was however not associated with aggression, and gender differences were not found in the relation of testosterone and cortisol with aggression.

The current finding that aggression is associated with high testosterone and low cortisol is in line with previous research (Dabbs et al., 1991; Glenn et al., 2011; Mehta \& Josephs, 2010; Popma, Vermeiren, et al., 2007; Tackett et al., 2014), and extends these findings to a larger sample of non-clinical adolescents. These results suggest that also normative, non-pathological levels of aggression in a general population of adolescents, may be related to the same neurobiological risk factors as for example violent aggression in incarcerated youths (Dabbs et al., 1991), aggression in delinquent boys (Popma, Vermeiren, et al., 2007), and psychopathic traits in adults (Glenn et al., 2011). Others, however, found no joint relation between testosterone, cortisol and aggression (Mazur \& Booth, 2014; Scerbo \& Kolko, 1994), or reported concurrent high testosterone and cortisol (Denson et al., 2012; Welker et al., 2014).

It is however important to note that in the current study the ratio of testosterone to cortisol was associated with aggressive behavior, and that the interaction between these hormones was not. With regard to previous studies, psychopathic traits were also found in relation to the ratio between testosterone and cortisol, but not the interaction (Glenn et al., 2011). However, an association was observed for the ratio of basal testosterone to cortisol reactivity only, whereas in the current study the ratio of basal testosterone to basal cortisol was associated with aggressive behavior. Romero-Martinez et al. (2013) investigated only the ratio surrounding a stress paradigm, and reported that intimate partner violence perpetrators had higher testosterone to cortisol ratios than controls, in preparation for, and after acute stress (Romero-Martinez et al., 2013). Mehta and Josephs (2010) reported an interaction indicating that high testosterone and low cortisol were associated with dominance in both a mixedgender sample and a male sample, as well as a marginally significant association with the ratio in the mixed-gender sample only (Mehta \& Josephs, 2010). Dabbs et al. (1991) and Popma, Vermeiren, et al. (2007) found an interaction indicating that high testosterone and low cortisol were associated with aggression in male offenders, although they did not examine the ratio between testosterone and cortisol. Several other studies also examined interactions only, but did not find associations with aggressive behavior (Mazur \& Booth, 2014; Scerbo \& Kolko, 1994), or found one in a different direction (Denson et al., 2012; Welker et al., 2014). In sum, to date, the ratio of testosterone to cortisol has been studied less often than the interaction, and results are inconsistent. The current results and those of Glenn et al. (2011) suggest that the ratio may better reflect the interconnectedness of the HPG and HPA axis than the interaction. Where the interaction describes the level of these hormones relative to the group, the ratio reflects the level of testosterone to the level of cortisol within an individual. As few studies examined both the ratio and 
the interaction, more research comparing these two different statistical approaches to investigate the joint relation of testosterone and cortisol is warranted.

The ratio of testosterone to cortisol could be interpreted as an index of the imbalance between the HPA and HPG axes within a specific individual. At a receptor level, both testosterone and cortisol bind to steroid-responsive centers in the amygdala (Wood, 1996). The amygdala has a key role in emotional processing (LeDoux, 2000), and where higher levels of testosterone facilitate fight/ approach reactions, higher levels of cortisol have an opposing effect by facilitating flight/fright reactions (Schulkin, 2003). Moreover, a high testosterone/cortisol ratio has been found to be associated with greater amygdala reactivity to facial signs of threat (Hermans et al., 2008), which in turn, biases one's propensity towards aggressive behavior (Carré, McCormick, \& Hariri, 2011; Coccaro, McCloskey, Fitzgerald, \& Phan, 2007). On the behavioral level, a disturbed balance towards higher testosterone over lower cortisol is thus indicative of more approach and less fear, increasing the likelihood of aggressive behavior. The additional variance in aggression explained by the ratio of testosterone to cortisol, than by cortisol alone, or cortisol controlled for testosterone, is however very small. This suggests that the effect of the ratio may be primarily driven by cortisol (controlled for testosterone). As the ratio of testosterone to cortisol is better at explaining the variance in aggressive behavior than cortisol (controlled for testosterone), the current findings do suggest that testosterone and cortisol jointly regulate aggressive behavior.

Although generally large gender differences exist in the levels of direct, particularly physical, aggressive behavior (Archer, 2004; Card, Stucky, Sawalani, \& Little, 2008), and testosterone levels are not only much lower in girls as compared to boys, but also produced differently (Burger, 2002), a lack of gender interactions were found in the current study. This is in line with previous research showing similar interactions for men and women in relation to dominance (Study 1, Mehta \& Josephs, 2010) and externalizing behavior (Tackett et al., 2014). When we examined boys and girls separately, for girls only the ratio remained significantly associated with aggressive behavior. Moreover, previous research indicated that psychopathic traits were associated with concurrent high testosterone and cortisol in men only (Welker et al., 2014). To further investigate gender differences in the relation between testosterone, cortisol and aggression, larger samples of boys and girls should be included in future studies.

The current non-clinical sample consists of adolescents derived from the general population. As at age 11 oversampling took place, this is not a strict general population sample. However, at age 17 merely $10 \%$ showed aggressive behavior in the borderline-clinical range, similar to $7 \%$ in the general population (Achenbach, 1991). Besides, the findings are similar when we examined the participants in the non-clinical range of aggressive behavior only. Moreover, the ratio between cortisol and testosterone only marginally distinguished severe aggression from normative levels of aggressive behavior. These results suggest that the testosterone/ cortisol ratio is related to all levels of aggressive behavior.

In contrast to many previous studies, the current sample consisted of adolescents. Dabbs et al. (1991), Popma, Vermeiren, et al. (2007), and Tackett et al. (2014) studied adolescents as well and reported an interaction for higher testosterone and lower cortisol. The ratio has not been studied previously in adolescents, and therefore needs replication for this developmental stage, especially as hormone levels increase drastically in puberty and aggression may further decrease in adulthood. However, at age 17, at which age the current study was performed, testosterone and cortisol have generally reached adult levels (Root, 1973). Aggressive behavior generally peaks in toddlerhood, and by age 17 has usually decreased to adult levels (Bongers, Koot, van der Ende, \& Verhulst, 2003; Nagin \& Tremblay, 1999). As previous studies also reported an increased ratio in relation to psychopathic traits and violence (Glenn et al., 2011; Romero-Martinez et al., 2013), it could be expected that this relation also holds in adult samples. As not all studies found a relation with the ratio (Mehta \& Josephs, 2010), the testosterone to cortisol ratio needs further examination in various age groups.

The results of the present study should be interpreted in the context of some limitations. First, testosterone and cortisol were analyzed from a single saliva sample, not enabling an average of several samples, which could have minimized the effect of pulsatility. These findings should be replicated in future studies assessing multiple samples on multiple days. Second, the sample size for boys appeared to be too small to detect an association between the testosterone/cortisol ratio and aggression. Although the current findings do point towards similar associations between the ratio of testosterone and cortisol in relation to aggression in both genders, more research in larger samples is necessary. Third, aggression was assessed with the Youth Self Report, this is a very broad measure of aggressive behavior, and does for instance not distinguish between reactive aggression and proactive aggression or verbal and physical aggression. Moreover, an experimental aggression paradigm would assess aggressive behavior more directly than a questionnaire. The advantage of the YSR, on the other hand, is that this is a highly valid, reliable and often used measure, and assesses aggressive behavior in various real-life 
situations. Fourth, cortisol and testosterone were assessed in saliva obtained after the participants had performed several tasks (e.g., an empathy task), which may modulate testosterone and cortisol concentrations, and perhaps differently depending on the level of aggression of participants. Saliva was, however, sampled within a standardized protocol and at the same time of day for all participants. As many studies obtain saliva within a testing protocol, future studies should not only standardize the time of day of sampling, but also sample saliva at valid resting conditions.

In conclusion, the current findings extend previous research by showing that the relation between aggression and high testosterone combined with low cortisol appears to represent variation along a spectrum that includes normative levels of aggression. The ratio of testosterone to cortisol could serve as a useful basis for further theories and studies to increase our understanding of aggression.

\section{REFERENCES}

Achenbach, T. M. (1991). Manual for the youth self-report and 1991 profile. Burlington, VT: University of Vermont, Department of Psychiatry.

Archer, J. (2004). Sex differences in aggression in real-world settings: A meta-analytic review. Review of General Psychology, 8, 291-322. doi: 10.1037/1089-2680.8.4.291

Archer, J., Graham-Kevan, N., \& Davies, M. (2005). Testosterone and aggression: A reanalysis of Book, Starzyk, and Quinsey's (2001) study. Aggression and Violent Behavior, 10, 241-261. doi: 10.1016/j. avb.2004.01.001

Alink, L. R. A., van Ijzendoorn, M. H., Bakermans-Kranenburg, M. J., Mesman, J., Juffer, F., \& Koot, H. M. (2008). Cortisol and externalizing behavior in children and adolescents: Mixed meta-analytic evidence for the inverse relation of basal cortisol and cortisol reactivity with externalizing behavior. Developmental Psychobiology, 50, 427-450. doi: $10.1002 /$ dev.20300

Bongers, I. L., Koot H. M., van der Ende, J., \& Verhulst, F. C. (2003). The normative development of child and adolescent problem behavior. Journal of Abnormal Psychology, 112, 179-192. doi: 10.1037/0021843X.112.2.179

Burger, H. G. (2002). Androgen production in women. Fertility and Sterility, 77 (Suppl 4), S3-S5. doi: 10.1016/S0015-0282(02)02985-0

Card, N. A., Stucky, B. D., Sawalani, G. M., \& Little, T. D. (2008). Direct and indirect aggression during childhood and adolescence: A metaanalytic review of gender differences, intercorrelations, and relations to maladjustment. Child Development, 79, 1185-1229. doi: 10.1111/ j.1467-8624.2008.01184.x

Carré, J. M., McCormick, C. M., \& Hariri, A. R. (2011). The social neuroendocrinology of human aggression. Psychoneuroendocrinology, 36, 935-944. doi: 10.1016/j.psyneuen.2011.02.001

Carsia, R. V., Reisch, N. M., Fennell, M. J., \& Weber, H. (1987). Adrenocortical function of the domestic fowl: Effects of orchiectomy and androgen replacement. Experimental Biology and Medicine, 185, 223-232. doi: 10.3181/00379727-185-42539

Coccaro, E. F., McCloskey, M. S., Fitzgerald, D. A., \& Phan, K. L. (2007). Amygdala and orbitofrontal reactivity to social threat in individuals with impulsive aggression. Biological Psychiatry, 62, 168-178. doi: 10.1016/j.biopsych.2006.08.024
Colby, H. D., Gaskin, J. H., \& Kitay, J. I. (1973). Requirement of the pituitary gland for gonadal hormone effects on hepatic corticosteroid metabolism in rats and hamsters. Endocrinology, 92, 769-774. doi: abs/ 10.1210/endo-92-3-769

Dabbs, J. M. J., Jurkovic, G. J., \& Frady, R. L. (1991). Salivary testosterone and cortisol among late adolescent male offenders. Journal of Abnormal Child Psychology, 19, 469-478. doi: 10.1007/BF00919089

De Vries-Bouw, M., Jansen, L. M. C., Vermeiren, R. R. J. M., Doreleijers, T. A. H., de Ven, P., \& Popma, A. (2012). Concurrent attenuated reactivity of alpha-amylase and cortisol is related to disruptive behavior in male adolescents. Hormones and Behavior, 62, 77-85. doi: 10.1016/ j.yhbeh.2012.05.002

Denson, T. F., Mehta, P. H., \& Ho, T. D. (2012). Endogenous testosterone and cortisol jointly influence reactive aggression in women. Psychoneuroendocrinology, 38, 416-424. doi: 10.1016/j.psyneuen.2012. 07.003

Glenn, A. L., Raine, A., Schug, R. A., Gao, Y., \& Granger, D. A. (2011). Increased testosterone-to-cortisol ratio in psychopathy. Journal of Abnormal Psychology, 120, 389-399. doi: 10.1037/a0021407

Hermans, E. J., Ramsey, N. F., \& van Honk, J. (2008). Exogenous testosterone enhances responsiveness to social threat in the neural circuitry of social aggression in humans. Biological Psychiatry, 63, 263-270. doi: 10.1016/j.biopsych.2007.05.013

Johnson, E. O., Kamilaris, T. C., Chrousos, G. P., \& Gold, P. W. (1992). Mechanisms of stress: A dynamic overview of hormonal and behavioral homeostasis. Neuroscience and Biobehavioral Reviews, 16, 115-130. doi: 10.1016/S0149-7634(05)80175-7

LeDoux, J. E. (2000). Emotion circuits in the brain. Annual Review of Neuroscience, 23, 155-184. doi: 10.1146/annurev. neuro.23.1.155

Mazur, A., \& Booth, A. (2014). Testosterone is related to deviance in male army veterans, but relationships are not moderated by cortisol. Biological Psychology, 96, 72-76. doi: 10.1016/j.biopsycho.2013. 11.015

McBurnett, K., Lahey, B. B., Rathouz, P. J., \& Loeber, R. (2000). Low salivary cortisol and persistent aggression in boys referred for disruptive behavior. Archives of General Psychiatry, 57, 38-43. doi: 10.1001/archpsyc.57.1.38

McCormick, C. M., Linkroum, W., Sallinen, B. J., \& Miller, N. W. (2002). Peripheral and central sex steroids have differential effects on the HPA axis of male and female rats. Stress: The International Journal on the Biology of Stress, 5, 235-247. doi: 10.1080/1025389021000061165

Mehta, P. H., \& Josephs, R. A. (2010). Testosterone and cortisol jointly regulate dominance: Evidence for a dual-hormone hypothesis. Hormones and Behavior, 58, 898-906. doi: 10.1016/j. yhbeh.2010.08.020

Montoya, E. R., Terburg, D., Bos, P. A., \& van Honk, J. (2012). Testosterone, cortisol, and serotonin as key regulators of social aggression: A review and theoretical perspective. Motivation and Emotion, 36, 65-73. doi: 10.1007/s11031-011-9264-3

Nagin, D., \& Tremblay, R. E. (1999). Trajectories of boys' physical aggression, opposition, and hyperactivity on the path to physically violent and nonviolent juvenile delinquency. Child Development, 70, 1181-1196. doi: 10.1111/1467-8624.00086

Nieuwbeerta, P. (2002). Crime victimization in comparative perspective. Den Haag, The Netherlands: Boom Juridische uitgevers.

Nowak, K. W., Neri, G., Nussdorfer, G. G., \& Malendowicz, L. K. (1995). Effects of sex hormones on the steroidogenic activity of dispersed adrenocortical cells of the rat adrenal cortex. Life Sciences, 57, 833837. doi: 10.1016/0024-3205(95)02015-B

Pajer, K., Tabbah, R., Gardner, W., Rubin, R. T., Czambel, R. K., \& Wang, Y. (2006). Adrenal androgen and gonadal hormone levels in adolescent girls with conduct disorder. Psychoneuroendocrinology, 31, 12451256. doi: 10.1016/j.psyneuen.2006.09.005 
Petersen, A. C., Crockett, L., Richards, M., \& Boxer, A. (1988). A selfreport measure of pubertal status: Reliability, validity, and initial norms. Journal of Youth and Adolescence, 17, 117-133. doi: 10.1007/ BF01537962

Platje, E., Jansen, L. M. C., Raine, A., Branje, S. J. T., Doreleijers, T. A. H., De Vries-Bouw, M., ... Vermeiren, R. R. J. M. (2013). Longitudinal associations in adolescence between cortisol and persistent aggressive or rule-breaking behavior. Biological Psychology, 93, 132-137. doi: 10.1016/j.biopsycho.2013.01.002

Popma, A., Doreleijers, T. A. H., Jansen, L. M. C., van Goozen, S. H. M., van Engeland, H., \& Vermeiren, R. R. J. M. (2007). The diurnal cortisol cycle in delinquent male adolescents and normal controls. Neuropsychopharmacology, 32, 1622-1628. doi: 10.1038/sj.npp.1301289

Popma, A., Vermeiren, R. R. J. M., Geluk, C. A. M. L., Rinne, T., van den Brink, W., Knol, D. L., ... Doreleijers, T. A. H. (2007). Cortisol moderates the relationship between testosterone and aggression in delinquent male adolescents Biological Psychiatry, 61, 405-411. doi: 10.1016/j.biopsych.2006.06.006

Romero-Martinez, A., Gonzalez-Bono, E., Lila, M., \& Moya-Albiol, L. (2013). Testosterone/cortisol ratio in response to acute stress: A possible marker of risk for marital violence. Social Neuroscience, 8 , 240-247.

Root, A. W. (1973). Endocrinology of puberty: I. Normal sexual maturation. The journal of Pediatrics, 83, 1-19.

Scerbo, A. S., \& Kolko, D. J. (1994). Salivary testosterone and cortisol in disruptive children: Relationship to aggressive, hyperactive, and internalizing behaviors. Journal of the American Academy of Child and Adolescent Psychiatry, 33, 1174-1184. doi: 10.1097/00004583199410000-00013

Schulkin, J. (2003). Rethinking homeostasis: Allostatic regulation in physiology and pathophysiology. Cambridge, MA: MIT Press.

Shoal, G. D., Giancola, P. R., \& Kirillova, G. P. (2003). Salivary cortisol, personality, and aggressive behavior in adolescent boys: A 5-year longitudinal study. Journal of the American Academy of Child and Adolescent Psychiatry, 42, 1101-1107. doi: 10.1097/01. CHI.0000070246.24125.6D
Tackett, J. L., Herzhoff, K., Harden, K. P., Page-Gould, E., \& Josephs, R. A. (2014). Personality $\times$ hormone interactions in adolescent externalizing psychopathology. Personality Disorders: Theory, Research, and Treatment, 5, 235. http://dx.doi.org/10.1037/per0000075

Terburg, D., Morgan, B., \& van Honk, J. (2009). The testosterone-cortisol ratio: A hormonal marker for proneness to social aggression. International Journal of Law and Psychiatry, 32, 216-223. doi: 10.1016/j.ijlp.2009.04.008

Tilbrook, A. J., Turner, A. I., \& Clarke, I. J. (2000). Effects of stress on reproduction in non-rodent mammals: The role of glucocorticoids and sex differences. Reviews of Reproduction, 5, 105-113. doi: 10.1530/ ror. 0.0050105

Van Honk, J., Harmon-Jones, E., Morgan, B. E., \& Schutter, D. J. (2010). Socially explosive minds: The triple imbalance hypothesis of reactive aggression. Journal of Personality, 78, 67-94. doi: 10.1111/j.14676494.2009.00609.x

Van Honk, J., \& Schutter, D. J. (2006). Unmasking feigned sanity: A neurobiological model of emotion processing in primary psychopathy. Cognitve Neuropsychiatry, 11, 285-306. doi: 10.1080/13546800500233728

Verhulst, F. C., van der Ende, J., \& Koot, H. M. (1997). Handleiding voor de Youth Self- Report. Rotterdam, Afdeling Kinder- en Jeugdpsychiatrie, Sophia Kinderziekenhuis/Academisch Ziekenhuis Rotterdam/ Erasmus Universiteit Rotterdam.

Viau, V. (2002). Functional cross-talk between the hypothalamic-pituitarygonadal and -adrenal axes. Journal of Neuroendocrinology, 14, 506513. doi: 10.1046/j.1365-2826.2002.00798.x

Viau, V., \& Meaney, M. J. (1996). The inhibitory effect of testosterone on hypothalamic-pituitary-adrenal responses to stress is mediated by the medial preoptic area. The Journal of Neuroscience, 16, 1866-1876.

Welker, K. M., Lozoya, E., Campbell, J. A., Neumann, C. S., \& Carré, J. M. (2014). Testosterone, cortisol, and psychopathic traits in men and women. Physiology and Behavior, 129, 230-236. doi: 10.1016/j. physbeh.2014.02.057

Wood, R. I. (1996). Functions of the steroid-responsive neural network in the control of male hamster sexual behavior. Trends in Endocrinology \& Metabolism, 7, 338-344. doi: 10.1016/S1043-2760(96)00155-5 